\title{
Evaluation of $\gamma$-oryzanol content and composition from the grains of pigmented rice-germplasms by LC-DAD-ESI/MS
}

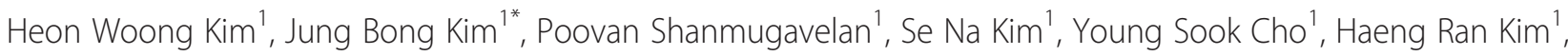
Jeong-Tae Lee ${ }^{2}$, Weon-Tai Jeon ${ }^{2}$ and Dong Jin Lee ${ }^{3}$

\begin{abstract}
Background: Rice is the staple food and one of the world's three major grain crops. Rice contains more than 100 bioactive substances including phytic acid, isovitexin, $\gamma$-oryzanol, phytosterols, octacosanol, squalene, $\gamma$-aminobutyric acid (GABA), tocopherol, tocotrienol derivatives, etc. Out of them, $\gamma$-oryzanol is known to have important biological profile such as anti-oxidants, inhibitor of cholesterol oxidation, reduce serum cholesterol levels in animals, effective in the treatment of inflammatory diseases, inhibit tumor growth, reduce blood pressure and promotes food storage stability when used as a food additive, etc. Hence in the present investigation, we aimed to evaluate the content and composition of $y$-oryzanol from pigmented rice germplasms using a liquid chromatography with diode array detection and electrospray ionization-mass spectrometry (LC-DAD-ESI/MS).

Findings: In the present study, 33 exotic pigmented rice accessions (red, white and purple) have been evaluated. Among them, the contents of $\gamma$-oryzanol varied from 3.5 to $21.0 \mathrm{mg} / 100 \mathrm{~g}$ with a mean of $11.2 \mathrm{mg} / 100 \mathrm{~g}$. A total of ten components of $\gamma^{-o r y z a n o l}$ including $\Delta^{7}$-stigmastenyl ferulate were identified of which, cycloartenyl ferulate, 24-methylenecycloartanyl ferulate, campesteryl ferulate and sitosteryl ferulate were identified as the major components. The mean proportions of steryl ferulates were in the descending order of 24-methylenecycloartanyl ferulate $>$ cycloartenyl ferulate $>$ campesteryl ferulate $>$ sitosteryl ferulate $>\Delta^{7}$-campestenyl ferulate $>$ campestanyl ferulate $>$ sitostanyl ferulate $>\Delta^{7}$-stigmastenyl ferulate $>$ stigamsteryl ferulate $>\Delta^{7}$-sitostenyl ferulate. Almost 11 accessions (33\%) showed higher content than the control rice Chucheongbyeo and higher proportions ranged from 10 to $15 \mathrm{mg} / 100 \mathrm{~g}$. Interestingly, the red rice accession Liberian Coll. B11/B-11 (21.0 mg/100 g) showed higher content -oryzanol than control rice Jeokjinjubyeo $(19.1 \mathrm{mg} / 100 \mathrm{~g})$ and the purple rice accession Padi Adong Dumarat, Mardi No.4376 (20.3 mg/100 g) showed a similar content with control rice Heugjinjubyeo (21.4 mg/100 g).

Conclusions: Most of analyzed rice accessions were found to possess higher contents of $y$-oryzanol than the control rice, Chucheongbyeo. In particular, the red accessions showed highest content than the white and purple accessions. The content and composition of $\gamma$-oryzanol in 33 exotic pigmented rice accessions have been evaluated and compared significantly by the present investigation.
\end{abstract}

\footnotetext{
* Correspondence: jungbkim@korea.kr

'Department of Agro-food Resources, National Academy of Agricultural Science, Rural Development Administration, Suwon 441-883, Republic of Korea

Full list of author information is available at the end of the article
} 


\section{Background}

Rice is the staple food for more than half the world's population and a valuable food resource as one of the world's three major grain crops. Particularly in Asia, it is a primary food source for most of the countries which can't be replaced by any other crops. However, the rice consumption is showing a considerable downward trend every year as a consequence of the westernization, diversification of dietary patterns and deprived consideration of the nutritional excellence of rice-based diets. Consequently, there is an essential need to upsurge the rice consumption and to solve the economic/social problems of farming communities by develop the rice varieties with more improved nutritional quality and functionality [1-3].

Generally, rice contains more than 100 bioactive substances mainly in its bran layer including phytic acid, isovitexin, $\gamma$-oryzanol, phytosterols, octacosanol, squalene, $\gamma$-aminobutyric acid (GABA), tocopherol, tocotrienol derivatives, and some new substances have also been identified and isolated from the rice accessions [4-6]. Out of them, $\gamma$-oryzanol (mixture of ferulic acid esters of triterpene alcohols and sterols) and lipid-soluble substances (tocopherol and tocotrienol) are known to be the most powerful anti-oxidants [7]. Remarkably, the total content of $\gamma$-oryzanol composition in rice bran is $13-20$ times higher than that of tocopherols and tocotrienols. Hence, they are known to have ten times higher anti-oxidant activity than tocopherol derivatives $[8,9]$. In addition, $\gamma$-oryzanol is a potent inhibitor of cholesterol oxidation [10-12], reduce serum cholesterol levels in animals [13-15], effective in the treatment of inflammatory diseases $[16,17]$, effective in anxiety neurosis and menopausal disorders [18-20], inhibit tumor growth [16,21], helps to lower blood pressure [22] and promotes food storage stability when used as a food additives $[23,24]$. On the other hand, ferulic acid esters are found in the seeds of grain crops such as rice, wild rice, corn, wheat, rye and barley. Among them, rice has been reported to contain most ferulic acid esters [25-29] which are well-known for their biological importance. In particular, pigmented rice has the functionality of pigments such as anthocyanin, procyanidin, catechin, catecholtannin, etc., and bioactive substances such as $\gamma$-oryzanol, phytosterols, octacosanol, etc., in the bran layer and thus provides excellent anti-oxidant activity compared to other common rice varieties [30-32].

At first, $\gamma$-Oryzanol was found in rice bran oil in 1954 [33] and it was thought that it consisted of a single component. Later, it was found to be a mixture of different components through a high performance liquid chromatographic analysis (HPLC). However, the number of identified individual components has varied depending on the chromatographic approaches. Diack et al. [34] attempted to separate $\gamma$-oryzanol into two fractions using a normal-phase HPLC on a silica column, but their approach failed to isolate and identify the individual components. In contrast, when reverse-phase HPLC was used, Norton et al. [35] and Miller et al. (2003) [36] succeeded in isolating the five different components and Evershed et al. [25] and Rogers et al. [37] succeeded in isolating the six different components. In view of this, recently a reverse-phase HPLC technique has successfully isolated and identified the ten different phytosteryl ferulates of $\gamma$-oryzanol including cycloartenyl ferulate, 24-methylenecycloartanyl ferulate and campesteryl ferulate as major components by $\mathrm{Xu}$ et al. [38]. Owing to fewer studies on the content and composition of $\gamma$-oryzanol in genetic resources and earlier chromatographic analysis involves limitations associated with low peak resolution, long analysis time and large sample size to detect minor components in brown rice, we were tempted to attain an analysis which suggests to irradiate the above limitations and involves a large-scale screening in the evaluation of genetic resources.

Thus, in connection with the above issues and in continuation of our earlier report on the evaluation of anthocyanins in colored potatoes by LC-DAD-ESI-MS [39], the present investigation intends to describe the evaluation of $\gamma$-oryzanol content and composition in the seeds of pigmented-rice genetic resources using a liquid chromatography associated with diode array detection and electrospray ionization-mass spectrometry [LC-DAD-ESI/MS].

\section{Findings}

Figure 1 shows the HPLC chromatograms of standard $\gamma$-oryzanol components and extracts from the seeds of control rice varieties, Chucheongbyeo (white rice) and Heugjinjubyeo (red rice). In the present study, a total of 10 components were isolated of which, cycloartenyl ferulate, 24-methylenecycloartanyl ferulate, campesteryl ferulate and sitosteryl ferulate were identified as the major components. Interestingly, herein analysis time was shortened to 40 minutes compared with previous report of 60 minutes and the peak retention time ranged between $15-30$ minutes $[38,40,41]$.

In particular, eight pigmented rice accessions have relatively higher content of $\gamma$-oryzanol with more than 15 mg/100 g. Padi Adong Dumarat Mardi No.4376, a purple rice accession showed a similar $\gamma$-oryzanol content of $20.3 \mathrm{mg} / 100 \mathrm{~g}$ to the control rice Heugjinjubyeo (21.4 mg/100 g), and $\gamma$ - Liberian Coll. B11/B-11, a red rice accession showed higher content of $21.0 \mathrm{mg} / 100 \mathrm{~g}$ than the control rice Jeokjinjubyeo $(19.1 \mathrm{mg} / 100 \mathrm{~g})$. The eight pigmented rice accessions showed higher $\gamma$-oryzanol content than control-group in the order of 4.5-6 times higher than Chucheongbyeo (3.5 mg/100 g), 2.5-3.5 times 

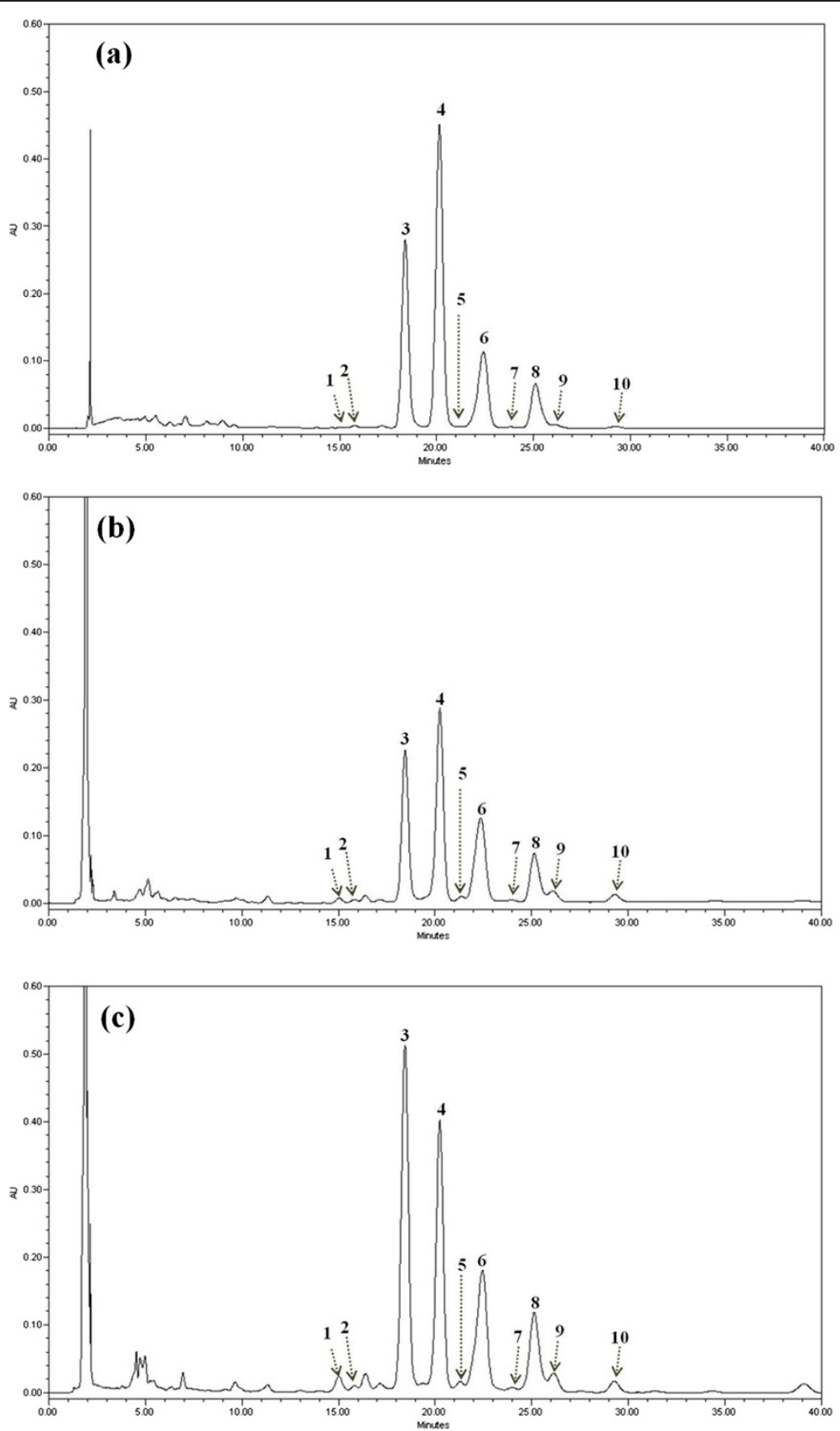

Figure 1 HPLC chromatograms of $\gamma$-oryzanol extracted from grains of the rice germplasm (1: $\Delta^{7}$-stigmastenyl ferulate, 2: stigamsteryl ferulate, 3: cycloartenyl ferulate, 4: 24-methylenecycloartanyl ferulate, $5: \Delta^{7}$-campestenyl ferulate, 6: campesteryl ferulate, 7: $\Delta^{7}$-sitostenyl ferulate, 8: sitosteryl ferulate, 9: campestanyl ferulate, 10: sitostanyl ferulate).

higher than Baekjinjubyeo $(6.1 \mathrm{mg} / 100 \mathrm{~g})$, and 1.8-2.5 times higher than Keunnunbyeo $(8.8 \mathrm{mg} / 100 \mathrm{~g})$ (Table 1). The chemical structure of each isolated component was derived on the basis of mass spectral information from GC-MS and LC-MS analysis [29,39]. When analysis was conducted in negative-ionization mode on a single quadrupole MS equipped with an ESI source, the forehead portion from the whole structure of each isolated component was found to appear as ferulic acid moiety $(m / z 177,178,193)$ based on fragment pattern of methyl group $\left(\mathrm{CH}_{3} ; m / z\right.$ 15) (Figure 2).

A reverse-phase HPLC analysis of 5 purple and 28 red rice accessions as pigmented-rice genetic resources showed the total contents of $\gamma$-oryzanol ranged from $3.5 \mathrm{mg} / 100 \mathrm{~g}$ to $21.0 \mathrm{mg} / 100 \mathrm{~g}$ with a mean of $11.2 \mathrm{mg} / 100 \mathrm{~g}$. This is less than half of the total contents of $30 \mathrm{mg} / 100 \mathrm{~g}$ [42] 
Table 1 Y-Oryzanol contents and compositions of steryl and triterpene alcohol ferulates in 33 pigmented rice germplasms collected from IRRI

\begin{tabular}{|c|c|c|c|c|c|c|c|c|c|c|c|c|c|}
\hline \multirow[t]{2}{*}{ Accessions } & \multicolumn{12}{|c|}{ Steryl and triterpene alcohol ferulates, proportions in total $\gamma$-oryzanol (\%) } & \multirow{2}{*}{$\begin{array}{c}\text { Y-oryzanol content } \\
\text { (mg/100 g hulled rice) }\end{array}$} \\
\hline & Origin & $\begin{array}{c}\text { Seed } \\
\text { coat color }\end{array}$ & $\begin{array}{l}\Delta^{7} \text {-stigma } \\
\text { stenyl } \\
\text { ferulate }\end{array}$ & $\begin{array}{l}\text { Stigma } \\
\text { steryl } \\
\text { ferulate }\end{array}$ & $\begin{array}{l}\text { 24-Methylene } \\
\text { cycloartanyl } \\
\text { ferulate }\end{array}$ & $\begin{array}{c}\text { Cyclo } \\
\text { artenyl } \\
\text { ferulate }\end{array}$ & $\begin{array}{l}\Delta^{7} \text {-campe } \\
\text { stenyl } \\
\text { ferulate }\end{array}$ & $\begin{array}{l}\text { Campe } \\
\text { Steryl } \\
\text { ferulate }\end{array}$ & $\begin{array}{c}\Delta^{7} \text {-sito } \\
\text { stenyl } \\
\text { ferulate }\end{array}$ & $\begin{array}{c}\text { Sito } \\
\text { Steryl } \\
\text { ferulate }\end{array}$ & $\begin{array}{l}\text { Campe } \\
\text { stanyl } \\
\text { ferulate }\end{array}$ & $\begin{array}{c}\text { Sito } \\
\text { stanyl } \\
\text { ferulate }\end{array}$ & \\
\hline Hill Padi Mardi No. 4337 & Malaysia & Purple & 3.2 & 1.4 & 26.6 & 31.8 & 10.9 & 13.5 & 0.3 & 8.6 & 2.3 & 1.4 & 17.9 \\
\hline Padi Adong Dumarat Mardi No. 4376 & Malaysia & Purple & 2.2 & 3.0 & 23.7 & 30.5 & 10.7 & 17.6 & 0.2 & 9.9 & 1.3 & 0.9 & 20.3 \\
\hline Tadong 1 & Malaysia & Purple & 1.2 & 0.5 & 29.7 & 28.7 & 8.5 & 17.1 & 0.3 & 11.7 & 1.3 & 1.0 & 8.8 \\
\hline Pulut Tindal ARC 818/57/85/222 & Malaysia & Purple & 1.4 & 1.3 & 29.0 & 28.0 & 6.5 & 16.3 & 0.7 & 9.6 & 4.5 & 2.8 & 12.3 \\
\hline Padi Pagalon MardiNo. 4370 & Malaysia & Red & 1.3 & 0.5 & 27.0 & 33.6 & 12.0 & 11.9 & 0.2 & 8.1 & 2.8 & 2.6 & 5.5 \\
\hline Paditarab. Arab Mardi No. 4400 & Malaysia & Red & 1.5 & 0.8 & 25.5 & 29.1 & 9.8 & 20.0 & 0.4 & 12.1 & 0.3 & 0.6 & 10.2 \\
\hline Akuramboda/5 BAD86 & Sri Lanka & Red & 1.6 & 1.7 & 13.8 & 36.5 & 18.2 & 17.2 & 0.3 & 7.3 & 2.4 & 1.1 & 15.1 \\
\hline Balawee/19-005 & Sri Lanka & Red & 1.3 & 1.1 & 22.3 & 41.2 & 5.2 & 16.8 & 0.1 & 8.4 & 2.1 & 1.5 & 17.8 \\
\hline Mada Al/19-001 & Sri Lanka & Red & 0.8 & 0.5 & 16.9 & 42.0 & 6.9 & 18.5 & 0.2 & 9.3 & 3.0 & 2.0 & 10.6 \\
\hline Kalu Galpa Wee & Sri Lanka & Red & 1.0 & 0.7 & 22.5 & 35.3 & 5.1 & 18.5 & N.D. ${ }^{a}$ & 9.4 & 4.9 & 2.6 & 8.8 \\
\hline Matta Thatwel/17/84/100 & Sri Lanka & Red & 0.5 & 0.2 & 20.2 & 37.1 & 14.5 & 8.7 & 1.0 & 8.5 & 5.1 & 4.3 & 7.9 \\
\hline 260 FAO ACC. 29. 793 & Liberia & Red & 1.0 & 0.5 & 23.4 & 30.4 & 11.7 & 17.2 & 0.3 & 9.8 & 3.6 & 2.0 & 4.3 \\
\hline 545 FAO ACC. 29. 832 & Liberia & Red & 1.2 & 1.1 & 38.3 & 23.2 & 3.2 & 16.1 & 0.2 & 10.8 & 3.6 & 2.4 & 6.1 \\
\hline Quakor/AGI-34 & Liberia & Red & 1.2 & 1.0 & 38.4 & 24.7 & 2.9 & 16.3 & 0.2 & 10.7 & 2.9 & 1.8 & 12.3 \\
\hline Sayllebon/3-150 & Liberia & Red & 0.9 & 1.4 & 32.7 & 27.8 & 3.5 & 17.5 & 0.3 & 10.3 & 3.6 & 2.2 & 7.8 \\
\hline Sayllebon/3-203 & Liberia & Red & 1.4 & 1.1 & 36.6 & 25.8 & 3.1 & 18.5 & 0.1 & 12.0 & 0.5 & 1.0 & 9.1 \\
\hline Liberian Coll. B11/B-11 & Liberia & Red & 1.5 & 0.9 & 34.9 & 25.4 & 3.6 & 16.7 & 0.1 & 10.8 & 3.6 & 2.5 & 21.0 \\
\hline Liberian Coll. D4-84/D4-84 & Liberia & Red & 1.4 & 1.2 & 34.7 & 26.9 & 4.0 & 15.5 & 0.5 & 11.4 & 2.8 & 1.8 & 12.2 \\
\hline Kwandwo Amoa & Ghana & Red & 2.9 & 1.2 & 24.5 & 31.1 & 11.3 & 16.0 & 0.3 & 8.9 & 2.5 & 1.5 & 16.7 \\
\hline Gbotokole Tos13129/YS137 & Ghana & Red & 1.3 & 0.4 & 28.2 & 30.0 & 9.1 & 15.5 & 0.2 & 10.7 & 2.8 & 1.8 & 1.9 \\
\hline Tinsibe/YS188 & Ghana & Red & 1.2 & 0.4 & 25.0 & 29.0 & 9.5 & 17.9 & 0.1 & 12.0 & 2.7 & 2.2 & 11.3 \\
\hline Beselen/YS678 & Ghana & Red & 1.1 & 0.5 & 28.6 & 28.7 & 8.5 & 14.8 & 0.2 & 10.6 & 4.3 & 2.8 & 14.1 \\
\hline IS16 TOS7542/IS16 & Ivory Coast & Red & 1.2 & 0.8 & 41.6 & 24.9 & 3.3 & 16.1 & 0.2 & 11.0 & 0.3 & 0.8 & 17.5 \\
\hline Sahima TOS9552/IS186 & Ivory Coast & Red & 1.1 & 0.4 & 25.0 & 30.9 & 10.9 & 15.8 & 0.2 & 10.3 & 3.1 & 2.2 & 10.0 \\
\hline Joboi TOS6984 & Sierra Leone & Red & 1.2 & 0.6 & 24.4 & 28.8 & 8.3 & 16.5 & 0.3 & 13.9 & 3.1 & 3.0 & 14.0 \\
\hline Koni TOS6922 & Sierra Leone & Red & 1.3 & 0.6 & 25.9 & 30.5 & 8.4 & 16.9 & 0.2 & 10.9 & 2.9 & 2.4 & 7.3 \\
\hline Gbondobai TOS7490/SL 11-288 & Sierra Leone & Red & 0.9 & 0.8 & 35.4 & 29.1 & 7.3 & 14.2 & 0.4 & 7.9 & 2.5 & 1.6 & 12.0 \\
\hline Gbonelobai TOS7501/SL 11-384 & Sierra Leone & Red & 1.1 & 0.6 & 36.3 & 28.3 & 6.7 & 12.2 & 0.2 & 9.8 & 2.6 & 2.3 & 5.7 \\
\hline ARC 13256 & India & Red & 1.1 & 0.7 & 21.1 & 36.1 & 12.6 & 12.7 & 0.6 & 8.6 & 3.7 & 2.9 & 3.5 \\
\hline Mamadou Salif TOS11927/SS628 & Senegal & Red & 1.6 & 1.2 & 32.8 & 28.6 & 4.6 & 16.5 & 0.3 & 8.5 & 3.8 & 2.1 & 15.3 \\
\hline
\end{tabular}


Table $1 \mathrm{p}$-Oryzanol contents and compositions of steryl and triterpene alcohol ferulates in $\mathbf{3 3}$ pigmented rice germplasms collected from IRRI (Continued)

\begin{tabular}{|c|c|c|c|c|c|c|c|c|c|c|c|c|c|}
\hline Bidjoco TOS10530/BS153 & Guinea Bissau & Red & 0.8 & 0.5 & 24.2 & 30.3 & 11.0 & 20.9 & 0.4 & 9.5 & 1.5 & 0.9 & 14.7 \\
\hline Boro 1 & Bangladesh & Red & 3.1 & 2.5 & 10.5 & 35.7 & 17.6 & 18.0 & 0.2 & 7.2 & 3.7 & 1.5 & 13.0 \\
\hline \multirow[t]{3}{*}{ Nanton53/PI245061 } & Taiwan & Purple & 1.2 & 1.0 & 29.1 & 32.0 & 9.2 & 14.1 & 0.2 & 8.7 & 2.9 & 1.7 & 4.0 \\
\hline & & Mean & 1.4 & 0.9 & 27.5 & 30.7 & 8.4 & 16.1 & 0.3 & 9.9 & 2.8 & 1.9 & 11.2 \\
\hline & & S.D. ${ }^{b}$ & 0.6 & 0.6 & 7.2 & 4.5 & 4.0 & 2.4 & 0.2 & 1.5 & 1.2 & 0.8 & 5.0 \\
\hline
\end{tabular}

${ }^{a}$ N.D. : Not detected.

b S.D. : Standard deviation. 

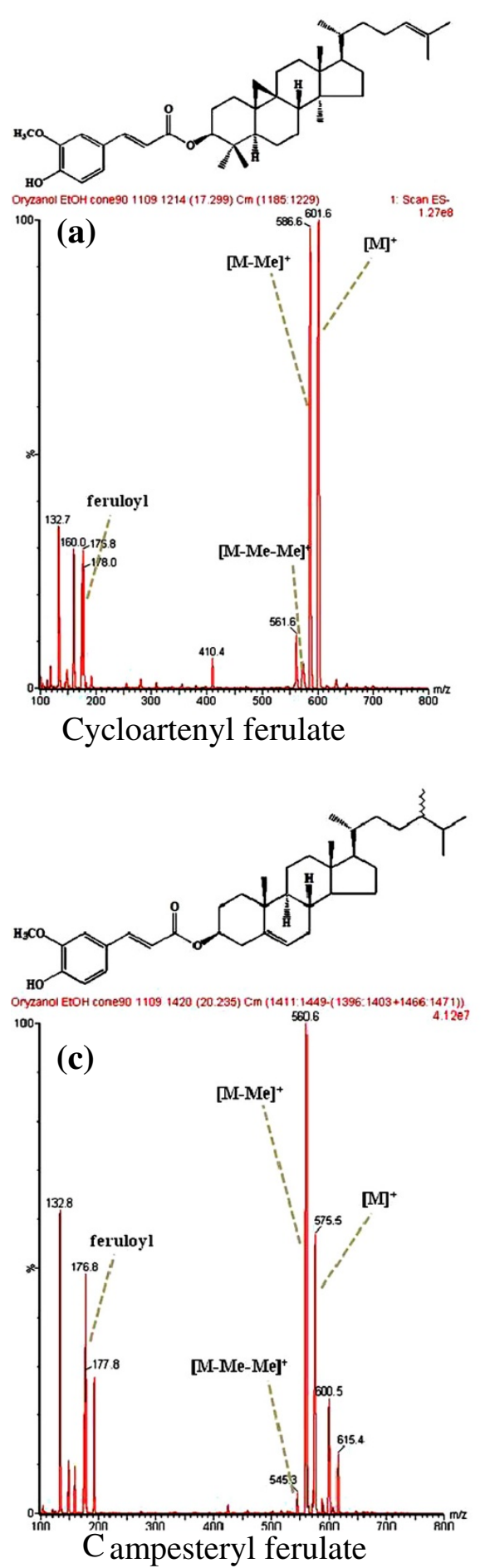

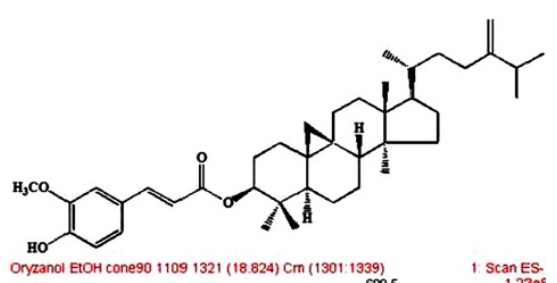

${ }^{100}$ (b)

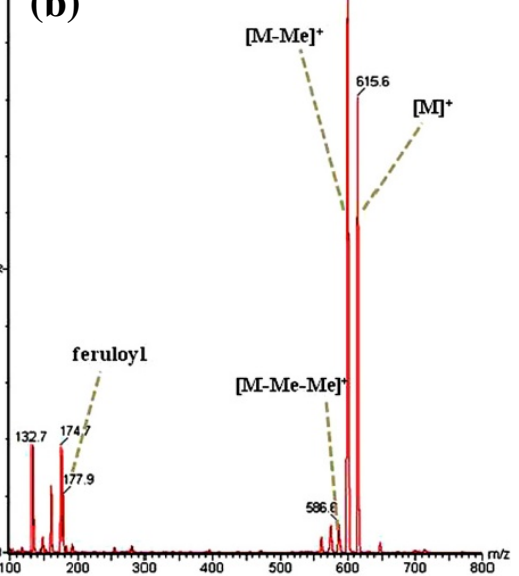

24-Methylenecycloartanyl ferulate

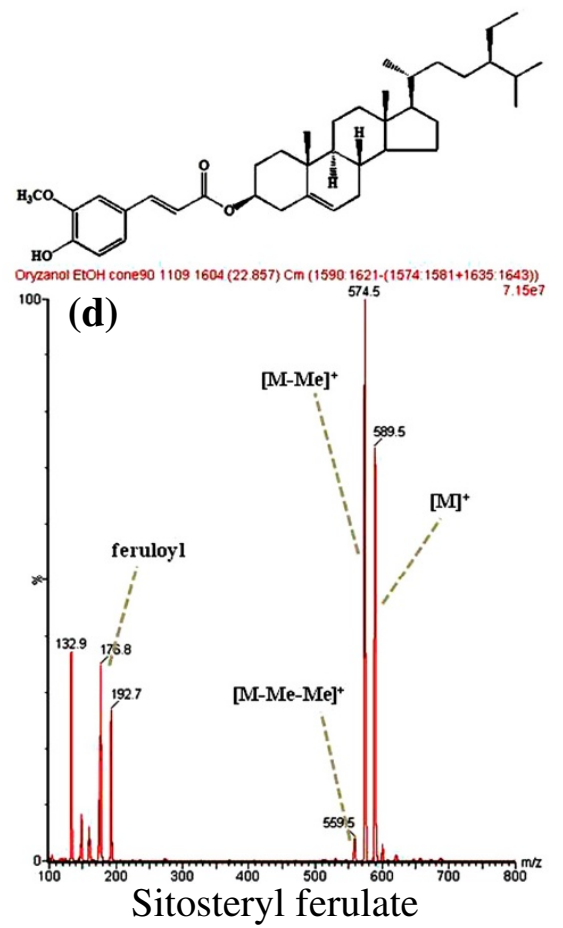

Figure 2 Structures and MS spectra of major -oryzanol components isolated from grains of Korean white rice cultivar, Chucheongbyeo.

and $40 \mathrm{mg} / 100 \mathrm{~g}$ [41] in earlier studies. This difference appears due to the differences between rice varieties or the number of peaks separated in the HPLC chromatogram and the area of each peak. The $\gamma$-oryzanol content was
$10-15 \mathrm{mg} / 100 \mathrm{~g}$ in 11 rice accessions (33\%) and less than $5 \mathrm{mg} / 100 \mathrm{~g}$ in four accessions (12\%). Most of the rice accessions showed a higher $\gamma$-oryzanol content than the control rice, chucheongbyeo $(3.5 \mathrm{mg} / 100 \mathrm{~g})$ (Table 2). 
Table 2 Y-Oryzanol contents and compositions of steryl and triterpene alcohol ferulates in 7 Korean rice samples (control rice varieties)

\begin{tabular}{|c|c|c|c|c|c|c|c|c|c|c|c|c|c|}
\hline \multirow[t]{2}{*}{ Accessions } & \multicolumn{12}{|c|}{ Steryl and triterpene alcohol ferulates, proportions in total $\gamma$-oryzanol (\%) } & \multirow{2}{*}{$\begin{array}{c}\text { Y-oryzanol content } \\
\text { (mg/100 g hulled rice) }\end{array}$} \\
\hline & Origin & $\begin{array}{l}\text { Seed } \\
\text { coat color }\end{array}$ & $\begin{array}{l}\Delta^{7} \text {-stigma } \\
\text { stenyl } \\
\text { ferulate }\end{array}$ & $\begin{array}{c}\text { Stigma } \\
\text { steryl } \\
\text { ferulate }\end{array}$ & $\begin{array}{l}\text { 24-Methylene } \\
\text { cycloartanyl } \\
\text { ferulate }\end{array}$ & $\begin{array}{c}\text { Cyclo } \\
\text { artenyl } \\
\text { ferulate }\end{array}$ & $\begin{array}{l}\Delta^{7} \text {-campe } \\
\text { stenyl } \\
\text { ferulate }\end{array}$ & $\begin{array}{l}\text { Campe } \\
\text { Steryl } \\
\text { ferulate }\end{array}$ & $\begin{array}{c}\Delta^{7} \text {-sito } \\
\text { stenyl } \\
\text { ferulate }\end{array}$ & $\begin{array}{c}\text { Sito } \\
\text { Steryl } \\
\text { ferulate }\end{array}$ & $\begin{array}{c}\text { Campe } \\
\text { stanyl } \\
\text { ferulate }\end{array}$ & $\begin{array}{l}\text { Sito stanyl } \\
\text { ferulate }\end{array}$ & \\
\hline Chucheongbyeo & Korea & White & 2.5 & 3.8 & 27.7 & 35.6 & 0.8 & 16.3 & 0.2 & 9.5 & 2.3 & 1.3 & 3.5 \\
\hline Kunnunbyeo & Korea & White & 5.1 & 2.7 & 23.2 & 32.5 & 13.0 & 10.3 & 1.2 & 8.8 & 1.8 & 1.6 & 8.8 \\
\hline Baekjinjubyeo & Korea & White & 1.1 & 0.7 & 30.5 & 33.6 & 6.3 & 13.0 & 0.1 & 9.4 & 2.8 & 2.6 & 6.1 \\
\hline Hanyangjo & Korea & Red & 1.1 & 0.6 & 20.8 & 35.8 & 12.9 & 15.4 & 0.1 & 7.2 & 4.5 & 1.8 & 14.3 \\
\hline Chosundo & Korea & Red & 1.5 & 1.6 & 20.7 & 30.4 & 10.1 & 19.7 & 0.7 & 11.9 & 2.1 & 1.3 & 13.6 \\
\hline Jeokjinjubyeo & Korea & Red & 1.5 & 1.2 & 37.2 & 28.6 & 4.3 & 16.2 & 0.3 & 10.3 & 0.2 & 0.4 & 19.1 \\
\hline \multirow[t]{3}{*}{ Heugjinjubyeo } & Korea & Purple & 0.9 & 2.6 & 36.8 & 29.9 & 0.5 & 15.9 & 0.3 & 8.3 & 3.0 & 1.8 & 21.4 \\
\hline & & Mean & 1.9 & 1.9 & 28.1 & 32.3 & 6.8 & 15.3 & 0.4 & 9.4 & 2.4 & 1.5 & 12.4 \\
\hline & & S.D. ${ }^{a}$ & 1.5 & 1.2 & 7.0 & 2.8 & 5.3 & 3.0 & 0.4 & 1.5 & 1.3 & 0.7 & 6.6 \\
\hline
\end{tabular}


Figure 3 describes the mean proportions of individual components of $\gamma$-oryzanol extracted from 33 pigmented rice accessions. The highest proportion was found in the order of 24-methylenecycloartanyl ferulate (23.17-41.96\%, mean $=30.7 \%)$, cycloartenyl ferulate $(10.47-41.59 \%$, mean $=$ $27.5 \%)$, campesteryl ferulate $(8.70-20.90 \%$, mean $=16.1 \%)$, sitosteryl ferulate $(7.22-13.85 \%$, mean $=9.9 \%), \Delta^{7}$ campestenyl ferulate $(2.87-18.19 \%$, mean $=8.4 \%)$, campestanyl ferulate $(0.25-5.06 \%$, mean $=2.8 \%)$, sitostanyl ferulate $(0.62-4.34 \%$, mean $=1.9 \%), \Delta^{7}$-stigmastenyl ferulate $(0.50-3.20 \%$, mean $=1.4 \%)$, stigamsteryl ferulate $(0.23-3.00 \%$, mean $=0.9 \%)$, and $\Delta^{7}$-sitostenyl ferulate $(0.09-0.66 \%$, mean $0.3 \%)$. The major $\gamma$-oryzanol components were found as cycloartenyl ferulate, 24-methylenecycloartanyl ferulate, campesteryl ferulate and sitosteryl ferulate in control rice varieties Heuginjubyeo and Jeokjinjubyeo. But, cycloartenyl ferulate was found as the highest proportion of total $\gamma$-oryzanol components in IS16 TOS7542/IS16, Heuginjubyeo, Tadong 1, Pulut Tindal ARC 818/57/85/222.

Figure 4 describes the scores plotting chart of principal components 1 and 2 of the PLS-DA results obtained from the data set by $\gamma$-oryzanol profiling on the red rice germplasms and thus we could identify overall patterns, variations and cluster formations at a glance. The plotting of PLS-DA scores for correlations between the content and composition of $\gamma$-oryzanol in 40 rice accessions collected from Africa and Asia region. It found no specific cluster formation in terms of seed coat color (white, red or purple), but 31 red-rice accessions showed cluster formations depending on the place of origin (East Africa and Southeast Asia) (Figure 4a). Principal component 1 (PC 1) and principal component 2 (PC 2) represented the variations of $31.5 \%$ and $24.5 \%$, respectively with a total of $56 \%$. The VIP value indicating a high importance $(\geq 1)$ in cluster formation which was highest in component 4 (24-methylenecycloartanyl ferulate, 1.57) followed by component 3 (cycloartenyl ferulate, 1.29), component 8 (sitosteryl ferulate, 1.14), and component $5\left(\Delta^{7}\right.$ campestenyl ferulate, 1.07) (Figure 4b) and thus, components 3, 4 and 8 were major and component 5 was minor component in their $\gamma$-oryzanol composition. For the strains belonging to six countries of Northwest coast of Africa (Ghana, Liberia, Sierra Leone, the Ivory Coast, Guinea Bissau and Senegal), cycloartenyl ferulate was found to higher than 24-methylenecycloartanyl ferulate in the proportion of individual components, whereas the accessions from four Southeast Asian countries (Sri Lanka, Malaysia, Bangladesh and India) were found to have higher proportions of 24-methylenecycloartanyl ferulates than cycloartenyl ferulates. Consequently, the main components, cycloartenyl ferulate and 24-methylenecycloartanyl ferulate were considered to have a major role in the formation of clusters by the place of origin. Further, upon the evaluation of genetic resources from a variety of regions, other individual components are also thought to play an important role as biomarkers.

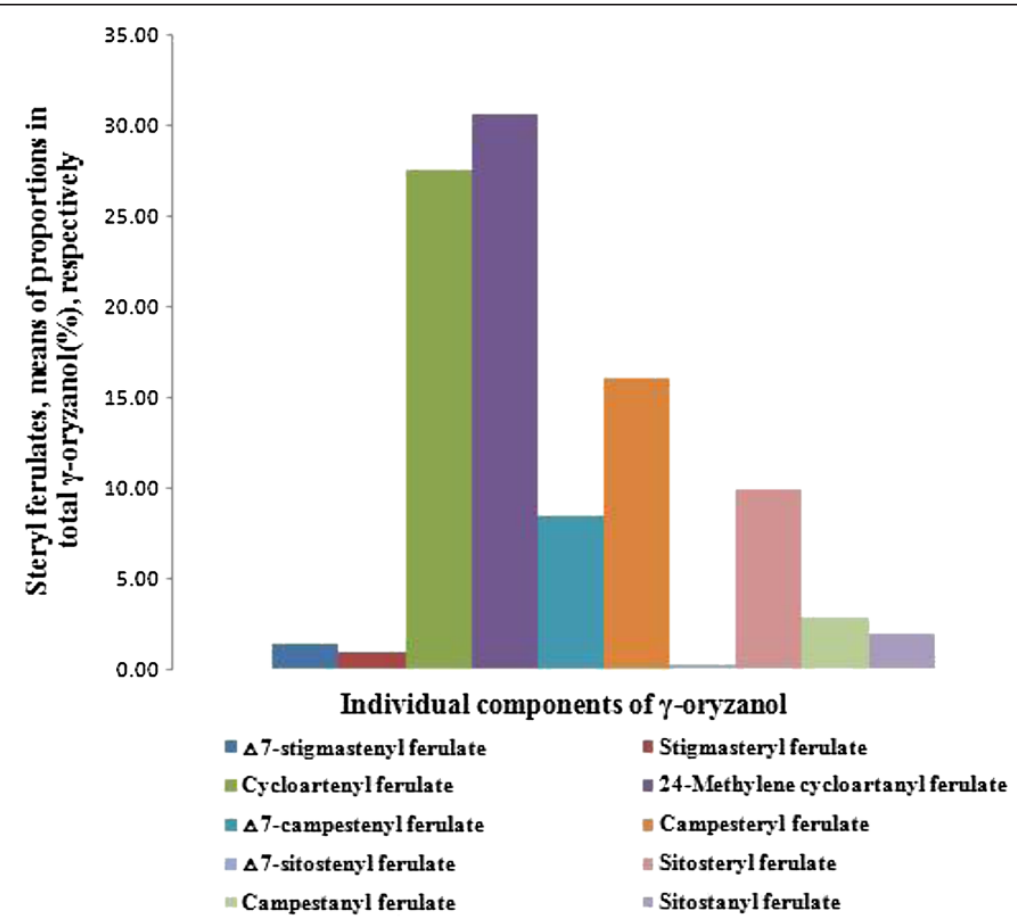

Figure 3 Comparison of the means proportions of total individual components (\%) isolated from the grains of pigmented rice germplasms. 

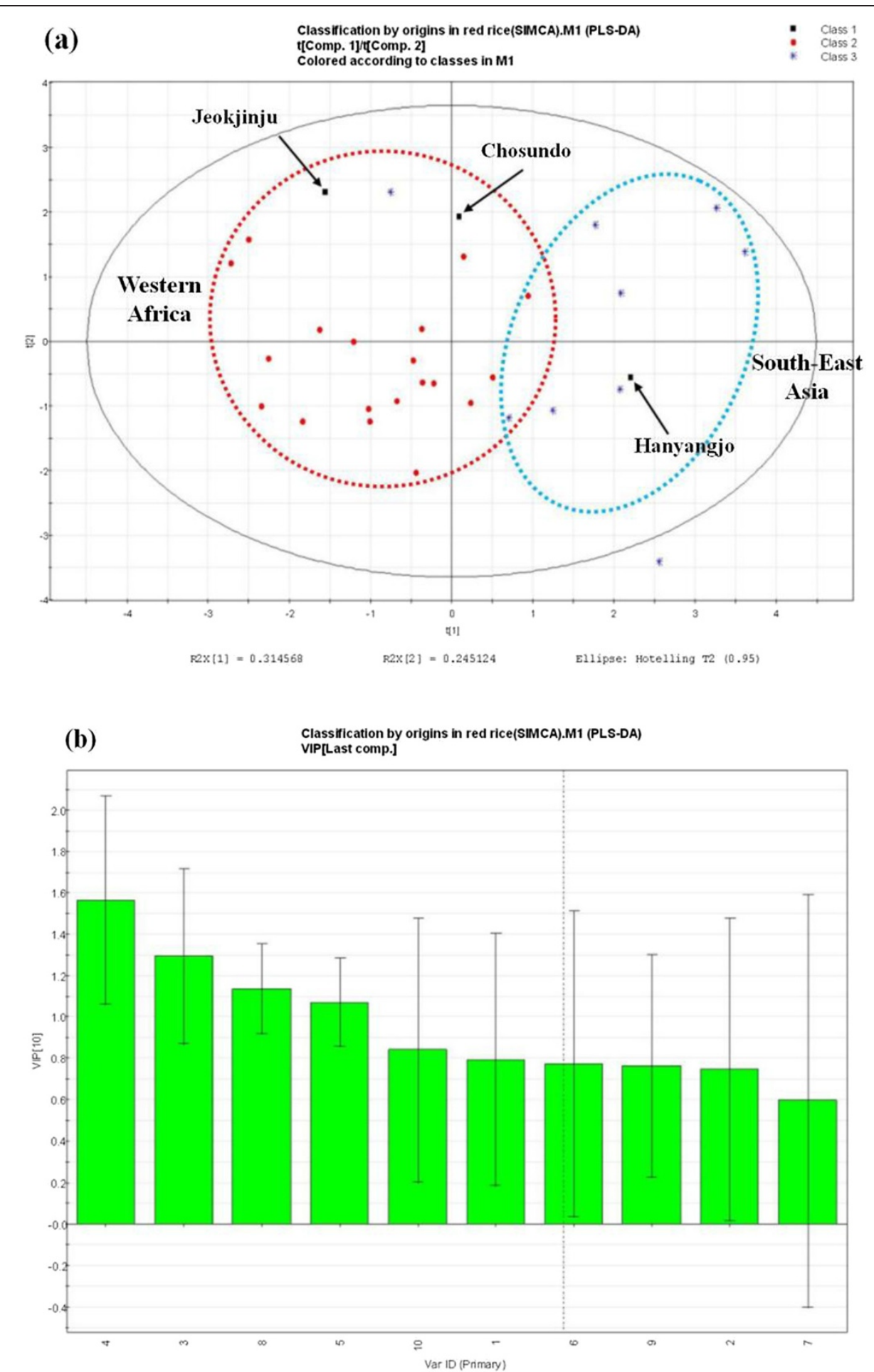

Figure 4 Scores plotting chart of principal components 1 and 2 of PLS-DA results obtained from the data set by $\gamma$-oryzanol profiling on the red rice germplasms. (a) classifications by origin of the all samples (red circle: Western Africa; blue triangle: South-East Asia; black box: Korean red rice cultivar), (b) influence of variable for this classifications (the value of variable importance in the prediction, VIP). 


\section{Conclusions}

In the present investigation, the analysis of contents and compositions of $\gamma$-oryzanol from 33 exotic pigmented rice accessions and 7 Korean rice varieties using LC-DAD-ESI/ MS has been accomplished. As a result, the contents of $\gamma$-oryzanol varied from 3.5 to $21.0 \mathrm{mg} / 100 \mathrm{~g}$ with a mean of $11.2 \mathrm{mg} / 100 \mathrm{~g}$. A total of ten components of $\gamma$-oryzanol including $\Delta^{7}$-stigmastenyl ferulate were identified of which, cycloartenyl ferulate, 24-methylenecycloartanyl ferulate, campesteryl ferulate and sitosteryl ferulate were identified as the major components. The mean proportions of steryl ferulates were in the descending order of 24-methylenecycloartanyl ferulate $>$ cycloartenyl ferulate $>$ campesteryl ferulate $>$ sitosteryl ferulate $>\Delta^{7}$-campestenyl ferulate $>$ campestanyl ferulate $>$ sitostanyl ferulate $>\Delta^{7}$ stigmastenyl ferulate $>$ stigamsteryl ferulate $>\Delta^{7}$-sitostenyl ferulate. Almost 11 accessions (33\%) showed higher content than the control rice Chucheongbyeo and higher proportions ranged from 10 to $15 \mathrm{mg} / 100 \mathrm{~g}$. Interestingly, the red rice accession Liberian Coll. B11/B-11 (21.0 mg/ $100 \mathrm{~g})$ showed higher content $\gamma$-oryzanol than control rice Jeokjinjubyeo $(19.1 \mathrm{mg} / 100 \mathrm{~g})$ and the purple rice accession Padi Adong Dumarat, Mardi No.4376 (20.3 mg/100 g) showed a similar content with control rice Heugjinjubyeo $(21.4 \mathrm{mg} / 100 \mathrm{~g})$. Most of analyzed rice accessions were found to possess higher contents of $\gamma$-oryzanol than the control rice, Chucheongbyeo. In genral, the red accessions showed highest content than the white and purple accessions.

\section{Materials and methods Materials}

In this study, 33 pigmented rice accessions (5 purple and 28 red accessions) and 7 Korean rice varieties (3 white, 3 red and 1 purple rice varieties) obtained from International Rice Research Institute (IRRI) were used for analysis. Hulled rices (whole grain) were used in this study.

\section{Instrumentation and reagents}

The instruments were used for the pretreatment process included a refrigerated multi-purpose centrifuge (Hanil Science Industrial Co. Ltd., Korea), and an ultrasonic bath (Daihan Scientific Co. Ltd., Korea). $\gamma$-Oryzanol (Wako, Japan) was used as an external standard. The HPLC reagents were methanol, dichloromethane, acetic acid and acetonitrile from Sigma (St. Louis, MO).

\section{Extraction of $\mathrm{y}$-Oryzanol}

A $5 \mathrm{~g}$ powdered sample in a conical tube $(50 \mathrm{~mL})$ was centrifuged $\left(3000 \mathrm{rpm}, 10 \mathrm{~min}, 4^{\circ} \mathrm{C}\right.$ ) following extraction with $40 \mathrm{ml}$ of dichloromethane-methanol $(2: 1, \mathrm{v} / \mathrm{v})$ for 30 minutes at $30^{\circ} \mathrm{C}$ in an ultrasonic shaking water bath. One millilitre of the supernatant solution was collected from the centrifuged sample. A Sep-Pak $\mathrm{C}_{18}$ cartridge was flushed with $10 \mathrm{~mL}$ of dichloromethane followed by the addition of $10 \mathrm{~mL}$ of methanol for activation. After loading $1 \mathrm{~mL}$ of supernatant ( $\gamma$-Oryzanol extract) and $1 \mathrm{~mL}$ of standard solution ( $\gamma$-Oryzanol, $1000 \mathrm{ppm}$ ), the cartridge was washed with $10 \mathrm{~mL}$ of dichloromethane and eluted with $1 \mathrm{~mL}$ of methanol. The $\gamma$-Oryzanol filtrate was eluted and concentrated using $\mathrm{N}_{2}$ gas, and then redissolved in dichloromethane-methanol $(2: 1, \mathrm{v} / \mathrm{v})$ prior to analysis with LC-DAD-ESI/MS.

\section{Quantitative and qualitative analysis of $\mathrm{Y}$-Oryzanol by LC-DAD-ESI/MS}

The quantitative and qualitative analysis $\gamma$-Oryzanol in the grains of red and purple rice accessions (whole grain) were analyzed using a Micromass ZQ MS (Waters Co., Milford, MA) and an Alliance e2695 HPLC system (Waters Co.) equipped with a 2998 photodiode array detector (PDA). In addition, YMC PACK ODS-AM reversed-phase column (4.6 x $250 \mathrm{~nm}$ I.D., $5 \mu \mathrm{m}$; YMC Co. Ltd, Japan) was used. The analysis was conducted at a flow rate of $1.4 \mathrm{ml} / \mathrm{min}$ in the detection wavelength of $250-400 \mathrm{~nm}$ (a representative wavelength of $325 \mathrm{~nm}$ ) with the column heater temperature of $30^{\circ} \mathrm{C}$. The mobile phases used were methanol: acetonitrile:dichloromethane: acetic acid (50:44:3:3, v/v/v/v) with isocratic elution for 40 minute. The MS was analyzed in negative ionization mode using electrospray ionization (ESI) source. The MS parameters were a cone voltage of $90 \mathrm{~V}$, source temperature of $100^{\circ} \mathrm{C}$, desolvation temperature of $500^{\circ} \mathrm{C}$, and a desolvation $\mathrm{N}_{2}$ gas flow of $480 \mathrm{l} / \mathrm{h}$. The range of molecular weights was $\mathrm{m} / \mathrm{z}, 100-800$ in full scan mode.

\section{Partial least squares discriminant analysis (PLS-DA)}

The SIMCA P+ software (version: 11, Umetrics $A B$, Umea, Sweden) for multivariate data analysis was used to acquire PLS-DA for discriminate the analyzed rice varieties by arranging and normalizing all quantitative information obtained in this study.

\section{Competing interests}

The authors declared that they have no competing interests.

\section{Authors' contributions}

HWK performed the experiments. PS, equally contributor who wrote the manuscript. JBK, corresponding author who guided \& supervised the work. SNK, YSC, HRK, LJT, JWT and DJL participated in designing of the work. All authors read and approved the final version of the manuscript.

\section{Acknowledgements}

This study was carried out with the support of "Research Program for Agricultural Science \& Technology Development (Project No.

PJ006430052012)", National Academy of Agricultural Science, Rural Development Administration, Republic of Korea.

\section{Author details}

${ }^{1}$ Department of Agro-food Resources, National Academy of Agricultural Science, Rural Development Administration, Suwon 441-883, Republic of Korea. ${ }^{2}$ National Institute of Crop Science, RDA, Suwon 441-857, Republic of 
Korea. ${ }^{3}$ Department of Crop Science and Biotechnology, Dankook University, Cheonan 330-714, Republic of Korea.

Received: 23 October 2012 Accepted: 9 April 2013

Published: 15 April 2013

\section{References}

1. Chae JC: Present status and prospect of crop production technology to improve the crop quality and functionality. Korean Soc Crop Sci 2002 47(5):1-14.

2. Korea Rural Economic Institute: Production and management of high quality rice. 2002:35.

3. Chae JC: Present situation, research and prospect of rice quality and bioactivity in Korea. Food Sci Ind 2004, 37(2):47-54.

4. Bidlack W: Phytochemicals as bioacive agents. Lancaster, Basel, Switzerland: Technomic Publishing Co., Inc; 1999:25-36.

5. Nam SH, Jang SM, Kang MY: Varietal difference in antioxidative activity of ethanolic extracts from colored rice bran. J Korean Soc Appl Biol Chem 2003, 46(1):16-22.

6. Chung YA, Lee JK: Antioxidative properties of phenolic compounds extracted from black rice. Korean Soc Food Sci Nutr 2003, 32(6):948-951.

7. Godber JS, Wells JH: Rice bran: as a viable source of high value chemicals. Louisiana Agriculture 1994, 37(2):13-17.

8. Bergman CJ, Xu Z: Genotype and environment effects on tocopherols, tocotrienols and gamma-oryzanol contents of Southern US rice. Cereal Chemistry 2003, 80(4):446-449.

9. Abdel-Aal ESM, Hucl P: A rapid method for quantifying total anthocyanins in blue aleurone and purple pericarp wheats. Cereal Chemistry 1999, 76:350-354

10. $\mathrm{X} U \mathrm{Z}$, Godber JS: Antioxidant activities of major components of $\mathrm{Y}$-oryzanol from rice bran using a linoleic acid model. JAOCS 2001, 78(6):645-649.

11. Miller A, Frenzel T, Schmarr HG, Engel KH: Development of an on-line LC-GC method for rapid analysis of $\gamma$-oryzanol in rice lipids. Norwich, UK: Euro food chem XI meeting; 2001:26-28.

12. Xu Z, Hua N, Godber JS: Antioxidant activity of tocopherols, tocotrienols, and $\gamma$ oryzanol components from rice bran against cholesterol oxidation accelerated by 2,2' azobis (2-methyl propionamidine)dihydrochloride. J Agric Food Chem 2001, 49:2077-2081.

13. Guardiola F, Codony R, Addis PB, Rafecas M, Boatella J: Biological effects of oxysterols: current status. Food Chem Toxicol 1996, 34(2):193-211.

14. Rong N, Ausman LM, Nicolosi RJ: Oryzanol decreases cholesterol absorption and aortic fatty streaks in hamsters. Lipids 1997, 32:303-309.

15. Yokoyama WH: Plasma LDL cholesterol lowering by plant phytosterols in a hamster model. Trends Food Sci Technol 2004, 15:528-531.

16. Akihisa T, Yasukawa K, Yamaura M, Ukiya Y, Kimura Y, Shimizu N, Arai K: Triterpene alcohol and sterol ferulates from rice bran and their antiinflammatory effects. J Agric Food Chem 2000, 48:2313-2319.

17. Chen $\mathrm{MH}$, Bergman $\mathrm{CJ}$ : A rapid procedure for analysing rice bran tocopherol, tocotrienol and $\gamma$-oryzanol contents. J Food Compos Anal 2005, 18:139-151.

18. Nakayama S, Manabe A, Suzuki J, Sakamoto K, Inagaki T: Comparative effects of two forms of $y$-oryzanol in different sterol compositions on hyperlipidemia induced by cholesterol diet in rats. Jpn J Pharmacol 1987, 44:135-144.

19. Rong N, Ausman LM, Nicholosi RJ: Rice bran oil decreases plasma LDL cholesterol by inhibitory dietary cholesterol absorption. FASEB J 1994, 8:303-309.

20. Sasaki J, Takada Y, Kusuda M, Tanabe Y, Matsunaga A, Arakawa K: Effects of y oryzanol on serum lipids and apolipoproteins in dyslipidemic schizophrenics receiving major tran quilizero. Clin Therap 1990, 12:263-268.

21. Yasukawa $K$, Akihisa T, Kimura Y, Tamura T, Takido M: Inhibitory effect of cycloartenol ferulate, a component of rice bran, on tumor promotion in two-stage carcinogenesis in mouse skin. Biol Pharm Bull 1998, 21:1072-1076

22. Tanaka A: Separation and quantitative analysis of ferulates. Yakagaku 1971, 20:792-799.

23. Nanua JN, McGregor JU, Godber JS: Influence of high-oryzanol rice bran oil on the oxidative stability of whole milk powder. J Dairy Sci 2000, 83:2426-2431

24. Kim JS, Godber JS: Oxidative stability and vitamin E levels increased in restructured beef roast with added rice bran oil. J Food Qual 2001, 24:17-26.
25. Evershed RP, Spooner N, Prescott M, Goad L: Isolation and characterization of intact steryl ferulates from seeds. J Chromatogr A 1988, 440:23-35

26. Seitz LM: Stanol and sterol esters of ferulic and p-coumaric acids in wheat, corn, rye and triticale. J Agric Food Chem 1989, 37:662-667.

27. Moreau RA, Powell MJ, Hicks KB, Norton RA: A comparison of the levels of ferulate-phytosterol esters in corn and other seeds. In Edited by Sanchez J, Cerda-Olmedo E, Martinez-Force E, Sanchez J, Cerda-Olmedo E, MartinezForce E. Spain: Universidad de Sevilla; 1998. Adv Plant Lip Res.

28. Hakala P, Lampi AM, Ollilainen V, Werner U, Murkovic M, Wahala K, Karkola $\mathrm{S}$, Piironen V: Steryl phenolic acid esters in cereals and their milling fractions. J Agric Food Chem 2002, 50:5300-5307.

29. Fang N, Yu S, Badger TM: Characterization of triterpene alcohol and sterol ferulates in rice bran using LC-MS/MS. J Agric Food Chem 2003, 51:3260-3267.

30. Akiwa Y, Ohtani T: Pigment properties of pigmented rices. Shokuhinggogyo 1991, 34:28-33.

31. Oki T, Masuda M, Kobayashi M, Nishiba Y, Furuta S, Suda I, Sato T: Polymeric procyanidins as radical-scavenging components in red-hulled rice. J Agric Food Chem 2002, 50:7524-7529.

32. Kang MY, Shin SY, Nam SH: Antioxidant and antioximutagenic activity with content of pigments and phenolic compounds of colored rice bran. Korean J Food Sci Technnol 2003, 35:968-974.

33. Kaneko R, Tsuchiya T: New compound in rice bran and germ oils. J Chem Soc Jpn 1954, 57:526-529.

34. Diack M, Saska M: Separation of vitamin E and $y$-Oryzanol from rice Bran b normal-phase chromatography. JAOCS 1994, 71(11):1211-1217.

35. Norton RA: Isolation and identification of steryl cinnamic acid derivatives from corn bran. Cereal Chem 1994, 71:111-117.

36. Miller A, Frenzel T, Schmarr HG, Engel KH: Coupled liquid chromatographygas chromatography for the rapid analysis of $\gamma$-oryzanol in rice lipids. J Chromatogr A 2003, 985:403-410.

37. Rogers EJ, Rice SM, Nicolosi RJ, Carpenter DR, McClelland CA, Romanczyk L: Identification and quantification of $\gamma$-oryzanol components and simultaneous assessment of tocols in rice bran oil. JAOCS 1993, 70:301-307.

38. Xu Z, Godber JS: Purification and identification of components of Y-oryzanol in rice bran oil. J Agric Food Chem 1999, 47:2724-2728.

39. Kim HA, Kim JB, Cho SM, Chung MN, Lee YM, Chu SM, Che JH, Kim SN, Kim SY, Cho YS, Kim JH, Park HJ, Lee DJ: Anthocyanin changes in the Korean purple-fleshed sweet potato, Shinzami, as affected by steaming and baking. Food Chem 2012, 130:966-972.

40. Miller A, Engel KH: Content of $\gamma$-oryzanol and composition of steryl ferulates in brown rice (Oryza sativa L.) of European origin. J Agric Food Chem 2006, 54:8127-8133.

41. Fujita A, Masumoto K, Kawakami K, Mikami T, Nomura M: Antioxidant activity of various rice brans. J Oleo Sci 2006, 55(11):585-591.

42. Shin T, Godber JS, Martin DE, Wells JH: Hydrolytic stability and changes in E Vitamers and oryzanol of excruded rice bran during storage. J Food Sci 1997, 62:704-708.

doi:10.1186/1756-0500-6-149

Cite this article as: Kim et al:: Evaluation of $\gamma$-oryzanol content and composition from the grains of pigmented rice-germplasms by LC-DAD-ESI/MS. BMC Research Notes 2013 6:149.

\section{Submit your next manuscript to BioMed Central and take full advantage of:}

- Convenient online submission

- Thorough peer review

- No space constraints or color figure charges

- Immediate publication on acceptance

- Inclusion in PubMed, CAS, Scopus and Google Scholar

- Research which is freely available for redistribution 